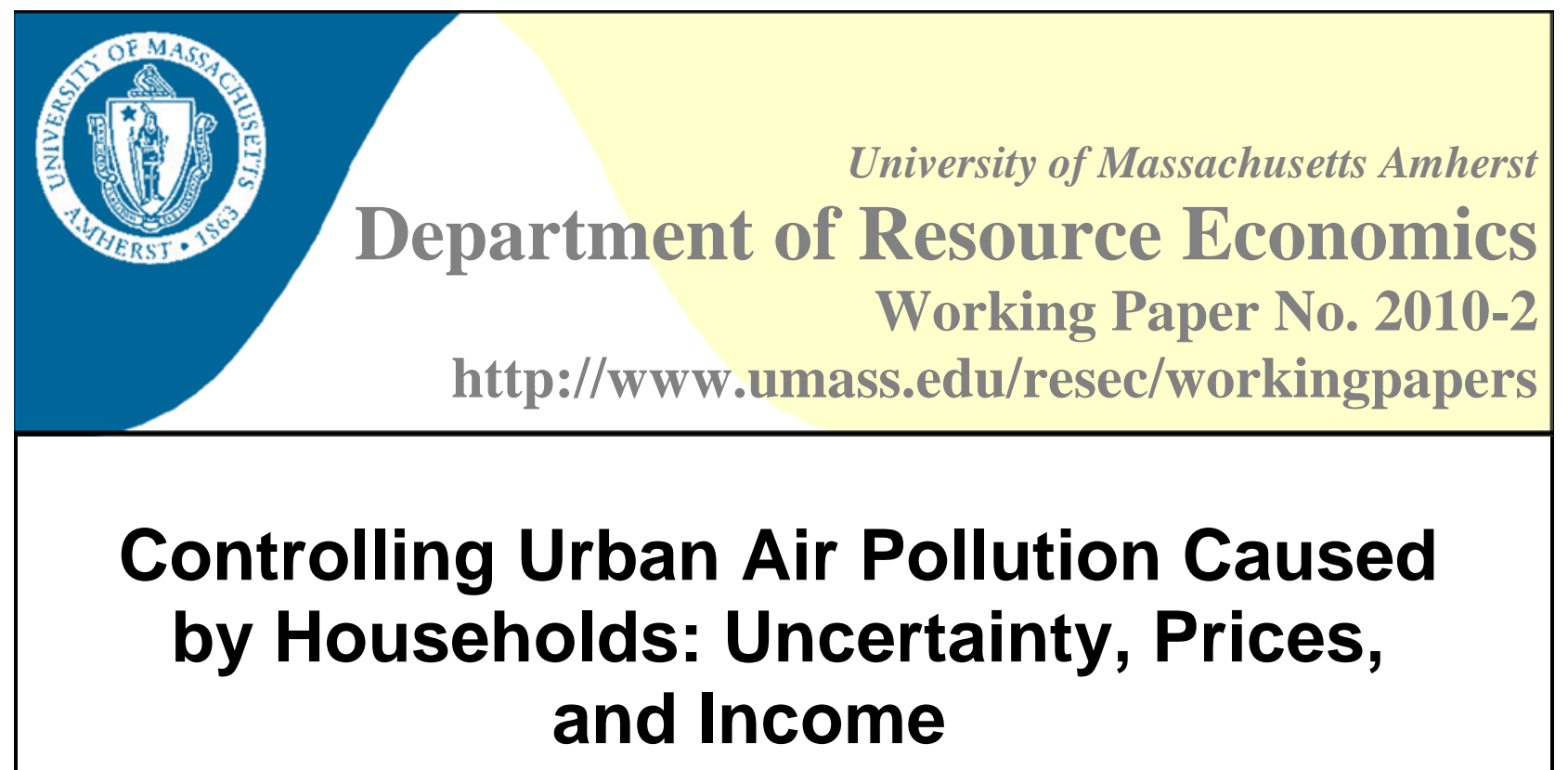

Carlos A. Chavez ${ }^{1}$, John K. Stranlund ${ }^{2}$, and Walter Gomez ${ }^{3}$

Abstract:

We examine the control of air pollution caused by households burning wood for heating and cooking in the developing world. Since the problem is one of controlling emissions from nonpoint sources, regulations are likely to be directed at household choices of wood consumption and combustion technologies. Moreover, these choices are subtractions from, or contributions to, the pure public good of air quality. Consequently, the efficient policy design is not independent of the distribution of household income. Since it is unrealistic to assume that environmental authorities can make lump sum income transfers part of control policies, efficient control of air pollution caused by wood consumption entails a higher tax on wood consumption and a higher subsidy for more efficient combustion technologies for higher income households. Among other difficulties, implementing a policy to promote the adoption of cleaner combustion technologies must overcome the seemingly paradoxical result that efficient control calls for higher technology subsidies for higher income households.

Keywords: efficiency, urban air pollution, nonpoint pollution, environmental policy, uncertainty JEL Classification: L51, H23, Q28

${ }^{1}$ Carlos A. Chavez, Departamento de Economia

Universidad de Concepcion

Casilla (Box) 1987, Concepcion, Chile

E: cchavez@udec.cl P: 56-41-2203067 F: 56-41-2254591

${ }^{2}$ John K. Stranlund, Department of Resource Economics

University of Massachusetts, 214 Stockbridge Hall

80 Campus Center Way, Amherst, MA 01003-9246

E: stranlund@resecon.umass.edu P: 413-545-6328 F: 413-545-5853

${ }^{3}$ Walter Gomez, Departamento de Ingenieria Matematica

Universidad de la Frontera

Temuco, Chile

E:wgomez@ufro.cl 
July, 2010

\title{
Controlling Urban Air Pollution Caused by Households: Uncertainty, Prices, and Income
}

\author{
Carlos A. Chávez* \\ Departamento de Economía \\ Universidad de Concepción. \\ John K. Stranlund \\ Department of Resource Economics \\ University of Massachusetts-Amherst \\ Walter Gómez \\ Departamento de Ingeniería Matemática \\ Universidad de la Frontera
}

\begin{abstract}
We examine the control of air pollution caused by households burning wood for heating and cooking in the developing world. Since the problem is one of controlling emissions from nonpoint sources, regulations are likely to be directed at household choices of wood consumption and combustion technologies. Moreover, these choices are subtractions from, or contributions to, the pure public good of air quality. Consequently, the efficient policy design is not independent of the distribution of household income. Since it is unrealistic to assume that environmental authorities can make lump sum income transfers part of control policies, efficient control of air pollution caused by wood consumption entails a higher tax on wood consumption and a higher subsidy for more efficient combustion technologies for higher income households. Among other difficulties, implementing a policy to promote the adoption of cleaner combustion technologies must overcome the seemingly paradoxical result that efficient control calls for higher technology subsidies for higher income households.
\end{abstract}

Keywords: Efficiency, urban air pollution, nonpoint pollution, environmental policy, uncertainty

\footnotetext{
* Correspondence to: Carlos Chávez, Departamento de Economía, Universidad de Concepción, Victoria 471, Barrio Universitario, Concepción, Chile. Phone: (56-41) 2203067, Fax: (56-41) 2254591, E-mail: cchavez@udec.cl.
} 


\section{Controlling Urban Air Pollution Caused by Households: Uncertainty, Prices, and Income}

\section{Introduction}

Air pollution caused by households burning wood for heating and cooking is a serious concern in many urban areas of the developing world. To illustrate the problem consider the city of Temuco, the capital city of the Araucanía region in southern Chile. This city contains about 350,000 people in about 86,000 households. It has been estimated that $90 \%$ of total emissions of suspended particulate matter in Temuco is caused by households burning 500,000 cubic meters of wood annually. There are about 100,000 smoke stacks connected to cooking and heating stoves in the city (Comisión Nacional del Medio Ambiente, CONAMA 2007, Chávez et. al 2009). The number of days that the concentration of total suspended particulate matter $\left(\mathrm{PM}_{10}\right)$ exceeded the 24-hour average Chilean legal limit of $150 \mu \mathrm{g} / \mathrm{m}^{3}$ was 11 in 2005, 15 in 2006, 21 in 2007, 36 in 2008, and 37 in 2009. Furthermore, during the 2009 season, the maximum daily average concentration on a 24 hour basis for the city was in the range of $800-1020 \mu \mathrm{g} / \mathrm{m}^{3}$. During the worst day of the 2009 season, the concentration of $\mathrm{PM}_{10}$ was measured at about 6090 $\mu \mathrm{g} / \mathrm{m}^{3}$ at 5 p.m., increasing to $6240 \mu \mathrm{g} / \mathrm{m}^{3}$ by 11 p.m. that same day. To put these figures in context, the Air Quality Guidelines of the World Health Organization (WHO) call for limiting the mean 24-hour concentration of $\mathrm{PM}_{10}$ in urban areas to $50 \mu \mathrm{g} / \mathrm{m}^{3}$ (WHO 2005).

Moreover, there are at least two reasons to be pessimistic about air quality in Temuco. First, generating household energy with kerosene or liquefied gas — the two closest substitutes for wood in central-southern Chile- is about 5 to 8 times more expensive than using fuel wood (Gómez-Lobo 2005). Second, the supply of wood from native forests surrounding the cities is also increasing, as many campesinos harvest wood to sell in urban areas. Even though an official figure of the number of campesinos supplying wood to Temuco is not available, the 
National Forest Service had registered about 470 producers. Most of these producers are owners of small plots of land less than 100 hectares (Lobos 2001 and Von Baer et. al. 2002). ${ }^{1}$

Situations like this pose major challenges for environmental regulatory authorities at local and national levels. The great number of individual sources of pollution makes direct emissions monitoring impractical; thus, air pollution from households is best characterized as a nonpoint pollution problem. The inability to monitor emissions implies that regulation is likely to be directed at emissions inputs, in particular wood consumption and household combustion technologies. In addition, regulators face a great deal of uncertainty because of stochastic weather effects on the concentration of air pollution and human health, and because of limited information about how households use combustion technologies and the wood input. Finally, choices of wood consumption or more efficient combustion technologies are subtractions from or contributions to a pure public good (i.e., air quality). It is well known by public economists that one cannot separate efficient provision of a public good from the distribution of income. (For example, see Laffont 1988, chapter 2). The main objective of this paper is to examine the role that income distribution plays in the determination of policies to control urban air pollution from households.

Our approach is to consider optimal taxes for wood consumption for household energy and subsidies for more energy efficient (less polluting) combustion technologies. We recognize that wood taxes or technology subsidies may not be implementable in particular instances,

\footnotetext{
${ }^{1}$ Air pollution problems caused by households burning wood for heating have also occurred in some regions of developed countries. Examples include the city of Christchurch in New Zealand (Barna and Gimson 2002, Environment Canterbury 2009, and Wilton et. al. 2006), the city of Launceston in Australia (Kesby et. al. 2002, Luhar et. al. 2006), Sacramento California (Sacramento Metropolitan Air Quality Management District 2006 and 2008), the town of Libby Montana (HPBA 2008), and British Columbia in Canada (Ministry of Environment-British Columbia 2005).
} 
because of monitoring, other information problems, and political realities. Nevertheless, deriving the optimal taxes and subsidies can yield important insights into the problem of controlling air pollution from households. ${ }^{2}$ In particular, we show that if authorities are able and willing to make unrestricted lump sum transfers of income among households, then these prices should be roughly equal across households. However, it is unrealistic to assume that lump sum income redistributions can be made part of a policy to control household air pollution. In the absence of lump sum transfers and assuming diminishing marginal utility of consumption of a private good, an optimal policy will force more of the burden of emissions control onto wealthier households. Thus, an optimal policy will charge a higher wood tax on wealthier households, as well as offer them a higher subsidy for the purchase of more efficient combustion technologies. This last result may seem paradoxical, but it is important to realize that the technology subsidy is not meant to correct income disparities-its purpose is to aid in the control of household pollution. The subsidy is higher for higher income households because this is an avenue by which more of the control burden is optimally placed on these households.

While the role that income distribution plays in the setting of environmental taxes has been well-studied by environmental economists, it is usually in the context of uniform taxes. Therefore, the question of how income distribution affects the distribution of control responsibilities is usually not addressed. ${ }^{3}$ One exception is Chichilnisky and Heal (1994) who examine how the global distribution of income affects the efficient distribution of greenhouse

\footnotetext{
${ }^{2}$ There is a proposed plan for the city of Temuco that offers subsidies to induce voluntary adoption of more efficient combustion technologies. The main feature is a subsidy-based stove exchange program to induce the renovation of 12,000 stoves over a ten year period (CONAMA 2007, Chapter II, Article 10).

${ }^{3}$ For example, this is true of Sandmo's (1975) classic article on optimal commodity taxation in the presence of an externality. Also see Bovenberg and Goulder (2002, section 5).
} 
gas abatement to confront climate change. They show that the familiar prescription that marginal abatement costs should be equal across countries only holds if countries commit themselves to large-scale transfers of income from richer to poorer nations. In the absence of these transfers the efficient distribution of abatement requires that richer countries undertake more abatement than would be implied by equalizing marginal abatement costs. ${ }^{4}$

Our contribution is that we examine the environmental policy/income distribution connection in the context of a nonpoint pollution problem. Chichilnisky and Heal (1994) assume perfect information about all benefits and costs of greenhouse gas control, while regulators have only limited information about these elements in the control of air pollution caused by households. More importantly, Chichilnisky and Heal (1994) assume that greenhouse gas emissions are perfectly observable. For our problem it is not practical to monitor household emissions; thus, control policies are likely to focus on controlling the inputs of the production of pollution, namely the fuel input and the combustion technology. There is an extensive literature on nonpoint pollution control, of which Shortle and Horan (2001) have provided a valuable review. However, we are not aware of any study that considers the impact of income distribution on the optimal control of a nonpoint pollutant. Our work makes this contribution to the nonpoint control literature in general, as well as to the study of the control of air pollution caused by households in the developing world in particular.

The rest of the paper proceeds as follows. In the next section we lay out a model of the control of air pollution caused by households burning wood for energy, and derive the optimal taxes on wood consumption and subsidies for more efficient combustion technologies. The main results of the paper are contained in section 3 where we examine the interdependence between

\footnotetext{
${ }^{4}$ Also see Heal, Chichilnisky and Starret (1993). Sheeran (2006) seeks to clarify certain aspects of Chichilnisky's and Heal's analysis.
} 
optimal policies and income distribution. We conclude in section 4 with an extended discussion of several implementation issues that our results generate.

\section{A model of regulating air pollution from households}

Consider an urban area consisting of a large number of households that produce energy by burning wood. Each household makes a small contribution to pollution levels, but the resulting aggregate level is dangerous for the community. Due to the large number of polluting households, an environmental authority is unable to measure emissions from each household. Consequently, we explore the design of taxes to induce lower wood consumption and subsidies to promote the adoption of cleaner-burning wood combustion technologies. ${ }^{5}$

\subsection{Basics of the model}

Let there be $n$ households indexed by $i$. Each household produces energy by combining a combustion technology, which we denote as $x_{i 1}$, and the amount of wood used, $x_{i 2}$. Thus, the production of energy in a household is given by

[1] $\quad c_{i}=c_{i}\left(x_{i 1}, x_{i 2}\right)$.

Assume that $c_{i}$ is increasing in fuel use $x_{i 2}$. We interpret $x_{i 1}$ as an index of available wood combustion technologies and order the technologies according to their effectiveness in producing energy given an amount of fuel. Assume that more effective combustion technologies are

\footnotetext{
${ }^{5}$ Another option would be to pursue an ambient pollution tax and subsidy as first proposed by Segerson (1988). This policy would involve household-specific penalties if the ambient concentration of air pollution surpasses some limit and subsidies if the concentration is lower than that limit. Despite the interest in these mechanisms for controlling nonpoint pollution, we are not aware of an instance in which they have been applied. Shortle and Horan (2001) discuss several practical limitations of these mechanisms.
} 
indicated by higher levels of $x_{i 1}$ so that $c_{i}$ is increasing in $x_{i 1}$. For analytic convenience we assume that $x_{i 1}$ is a continuous variable. ${ }^{6}$ There may very well be uncertainty from a regulator's perspective about $c_{i}$, perhaps because of unobservable skill levels or wood quality, but we ignore this possibility because households' energy production is not our primary concern.

Our main concern is that energy production creates emissions of pollution, $r_{i}$, as a byproduct. Thus, household emissions depend on the combustion technology, the wood input, and a random parameter $\sigma_{i}$ (from a regulator's point of view) that captures unobserved variation in how the combustion equipment is actually used: [2] $r_{i}=r_{i}\left(x_{i 1}, x_{i 2}, \sigma_{i}\right)$.

Suppose that $r_{i}$ is increasing in the amount of wood used, but is decreasing in the combustion technology (under the assumption that a more productive combustion technology burns more cleanly and uses less wood for the amount of energy generated). The random parameter $\sigma_{i}$ represents households' preferences and skills that affect how the combustion equipment is used, and consequently the production of emissions. For example, emissions are an increasing function of the moisture content of the wood used, and households choose wood with varying moisture content. ${ }^{7}$ Furthermore, households can adjust the amount of wood burned per period of time by varying the air flow in and out of the combustion equipment. Reducing airflow increases burn time but also increases emissions. Overfilling the combustion chamber with

\footnotetext{
${ }^{6}$ Assuming that the combustion technology is a continuous variable may not be too far from the truth. Combustion technologies can vary along several dimensions including type, size, vintage, and so on. Treating each combination of characteristics as a distinct technology can produce a large number of technologies that, when ordered according to energy-producing efficiency, can be modeled as being on a continuum.

${ }^{7}$ It has been reported in the city of Temuco that some households actually prefer to use wetter wood even though it has lower caloric content, because moist wood burns slower and lasts longer (Chávez et. al. 2009, CONAMA-DICTUC 2008, CONAMA 2007, Nussbaumer 2006).
} 
wood to avoid frequent refilling can also produce higher emissions (Klippel and Nussbaumer 2007; Nussbaumer 2003 and 2006).

Environmental quality in a city depends on the ambient concentration of pollution. The main pollutants produced from burning wood are nitrogen oxide, carbon monoxide, and fine particulate matter. To simplify matters, we assume that household emissions produce a single pollutant. In addition we assume that this pollutant is uniformly mixed; that is, the ambient concentration of the pollutant depends only on the sum of household emissions. This assumption makes the location of emissions irrelevant, which is a reasonable approximation for pollution problems in the cities that motivate this work. ${ }^{8}$ Let the ambient concentration of the pollutant be

$$
a=a\left(\sum_{k=1}^{n} r_{k}\left(x_{k 1}, x_{k 2}, \sigma_{k}\right), \theta\right),
$$

which is increasing in aggregate household emissions so it is increasing in individual household emissions as well. The parameter $\theta$ is a random factor that captures the effect of weather conditions on air quality. For example, windy days result in lower ambient pollution for a given level of emissions because pollution is blown away and dispersed. However, cold can produce a thermal inversion that traps pollutants at ground level, resulting in higher ambient concentration of pollution.

The utility function for a household is denoted by

$$
u_{i}=u_{i}\left(c_{i}, y_{i}, a, \mu, \eta_{i}\right)
$$

\footnotetext{
${ }^{8}$ As noted in the introduction our work is motivated by household pollution problems in urban areas of the central-southern region of Chile. Most of these areas are located in the central valley, on relatively flat land surrounded by small hills, away from the Los Andes mountain range. The many emission points are quite uniformly distributed within each city. We should note that the model can be easily modified to consider non-uniformly mixed pollutants.
} 
Suppose that utility is increasing in energy use $c_{i}$ and the consumption of a private commodity $y_{i}$, but is decreasing in ambient pollution $a$. Note that since the ambient concentration of pollution affects each household's utility, their choices of combustion technology and wood consumption can be viewed as contributions to and subtractions from the local public good of air quality. The variable $\mu$ is a random parameter that captures the notion that weather affects household energy choices. Think of households generating more energy to heat their homes when it is colder. We assume for simplicity that the distributions of the random weather parameters, $\mu$ and $\theta$, are known to all households as well as to the regulator. The last term in a household's utility function, $\eta_{i}$, is a random term from the regulator's perspective that represents unobservable household characteristics that affect its production of energy, like the insulation of the house, preferences for the type of combustion equipment, and preferences for warmth.

Each household faces a set of prices for the combustion technology and wood input, which we denote as $p_{1}$ and $p_{2}$, respectively. To keep the model tractable and focused we assume that these prices are fixed throughout. Relaxing this assumption would not change the fundamental insights of this paper about the role of income distribution in the design of policies to control household air pollution. The price of the private consumption good is equal to one.

We further simplify the analysis by assuming that each household $i$ has exogenous income $\bar{w}_{i}$, which is taxed at an exogenous rate $z_{i}$. Income taxes are fixed because real environmental agencies do not have the authority to make income transfers a part of environmental regulations. We will see later that this assumption plays a very important role in policy formation. 
We can obtain principles for controlling urban air pollution from households by deriving the optimal subsidies on combustion technologies and taxes on wood. Anticipating that optimal taxes/subsidies could vary across households, denote the subsidy on household $i$ 's combustion technology as $t_{i 1} \leq 0$, and its tax on each unit of wood used as $t_{i 2} \geq 0$. Household specific after subsidy/tax prices on combustion technologies and wood are $p_{1}+t_{i 1}$ and $p_{2}+t_{i 2}, i=1, \ldots, n$, respectively.

Given the after subsidy/tax prices on combustion and wood, a household's budget constraint is

$$
\bar{w}_{i}\left(1-z_{i}\right)=y_{i}+\left(p_{1}+t_{i 1}\right) x_{i 1}+\left(p_{2}+t_{i 2}\right) x_{i 2} .
$$

We do not examine how income taxes affect the optimal prices on combustion technologies and wood input, but we do assume that the government can fund the household pollution control program. To that end assume

$$
\sum_{i=1}^{n} \bar{w}_{i} z_{i} \geq \sum_{i=1}^{n} t_{i 1} x_{i 1}+\sum_{i=1}^{n} t_{i 2} x_{i 2} ;
$$

that is, the government's income tax receipts are sufficient to meet the revenue requirements of the household pollution control program. If aggregate subsidy payments exceed the aggregate taxes on the wood input, then the difference is financed out of income tax receipts. If wood tax receipts exceed subsidies for more efficient combustion technologies, then the excess is simply added to the government's budget.

\subsection{Household energy input choices}

A household's decision problem is to choose a combustion technology, wood input, and consumption of the private good to maximize its expected utility subject to [1], [3], and [5]. That 
is, a household chooses $x_{i 1}, x_{i 2}$, and $y_{i}$ to solve:

[6] $\quad \max E_{i}\left(u_{i}\left(c_{i}, y_{i}, a, \mu, \eta_{i}\right)\right)$

s.t. $\quad c_{i}=c\left(x_{i 1}, x_{i 2}\right)$

$$
\begin{aligned}
& w_{i}=y_{i}+\left(p_{1}+t_{i 1}\right) x_{i 1}+\left(p_{2}+t_{i 2}\right) x_{i 2} \\
& a=a\left(\sum_{k=1}^{n} r_{k}\left(x_{k 1}, x_{k 2}, \sigma_{k}\right), \theta\right),
\end{aligned}
$$

where $w_{i}=\bar{w}_{i}\left(1-z_{i}\right)$ is the household's after tax income, $E_{i}$ denotes the expectation operator for household $i$. This expectation is with respect to the joint distribution of $\left(\mu, \theta, \eta_{1}, \ldots, \eta_{i-1}, \eta_{i+1}, \ldots, \eta_{n}, \sigma_{1}, \ldots, \sigma_{i-1}, \sigma_{i+1}, \ldots, \sigma_{n}\right)$, conditional on $\eta_{i}$ and $\sigma_{i}$. Substituting the constraints of [6] into its objective allows us to write the household's problem as choosing $x_{i 1}$ and $x_{i 2}$ to maximize

$$
E_{i}\left\{u_{i}\left(c_{i}\left(x_{i 1}, x_{i 2}\right), w_{i}-\left(p_{1}+t_{i 1}\right) x_{i 1}-\left(p_{2}+t_{i 2}\right) x_{i 2}, a\left(\sum_{k=1}^{n} r_{k}\left(x_{k 1}, x_{k 2}, \sigma_{k}\right), \theta\right), \mu, \eta_{i}\right)\right\} .
$$

Assume that the following first-order conditions determine each household's optimal choices of combustion technology and wood consumption, given these choices by all the other households in the city:

$$
E_{i}\left\{\frac{\partial u_{i}}{\partial c_{i}} \frac{\partial c_{i}}{\partial x_{i j}}-\frac{\partial u_{i}}{\partial y_{i}}\left(p_{j}+t_{i j}\right)+\frac{\partial u_{i}}{\partial a} \frac{\partial a}{\partial r_{i}} \frac{\partial r_{i}}{\partial x_{i j}}\right\}=0, i=1, \ldots, n, j=1,2 .
$$

These first order conditions implicitly define Bayes-Nash best response functions, and the solution to these $2 n$ equations, assuming that one exists, gives us a Bayes-Nash equilibrium distribution of wood use and combustion technologies in the urban area. The first-order conditions reveal that each household will optimally choose the level of combustion technology 
and input use considering three elements; the marginal utility of the combustion technology or wood use in the generation of energy, the marginal reduction in utility from the reduction in spending on other private goods, and the marginal impact that the choice of technology or wood use has on the pollution damage the household experiences. To the extent that the household can detect a change in ambient pollution from its own emissions (i.e., $\partial a / \partial r_{i}>0$ ), the choice of a more efficient combustion technology reduces the pollution damage it suffers (because $\partial r_{i} / \partial x_{i 1}<0$ ) while an increase in its use of wood increases the damage it suffers (because $\partial r_{i} / \partial x_{i 2}>0$ ), holding the choices of all other households constant. Note that $\partial a / \partial r_{i}>0$ is the same for all $i$, because of our assumption that ambient pollution depends only on the sum of households’ emissions.

\subsection{Efficient household choices}

Optimal wood taxes and combustion technology subsidies internalize the external costs and benefits of the households' choices. To determine the taxes and subsidies that will induce an efficient allocation of energy choices, we first derive an efficient allocation of wood use and combustion choices by maximizing an expected Bergson-Samuelson social welfare function. ${ }^{9}$ That is we choose $\left(x_{i 1}, x_{i 2}\right), i=1, \ldots, n$ and $j=1,2$, to solve

[9] $\max E_{g}\left(\sum_{i=1}^{n} \lambda_{i} u_{i}\left(c_{i}, y_{i}, a, \mu, \eta_{i}\right)\right)$,

s.t. $\quad c_{i}=c\left(x_{i 1}, x_{i 2}\right), i=1, \ldots, n$,

\footnotetext{
${ }^{9}$ The alternative method for finding efficient allocations is to maximize the expected budgetconstrained utility of one household while holding the expected budget-constrained utilities of the other households constant. Our results do not depend on maximizing a social welfare function, because the alternative methods are functionally equivalent.
} 


$$
\begin{aligned}
& w_{i}=y_{i}+p_{1} x_{i 1}+p_{2} x_{i 2}, i=1, \ldots, n, \\
& a=a\left(\sum_{k=1}^{n} r_{k}\left(x_{k 1}, x_{k 2}, \sigma_{k}\right), \theta\right),
\end{aligned}
$$

In the objective of [9], $\lambda_{i}>0, i=1, \ldots, n$, are exogenous household utility weights. $E_{g}$ refers to the expectation operator for the environmental authority, which is with respect to the joint distribution of $\left(\mu, \theta, \sigma_{1}, \ldots, \sigma_{n}, \eta_{1}, \ldots, \eta_{n}\right)$. Our inclusion of household budget constraints in this problem (instead of, for example, posing production functions for combustion technologies and fuel wood) reflects the notion that an environmental agency with limited authority must design a control policy, given the existing distribution of income and income taxes, and the supplies of combustion technologies and fuel wood. In particular, we do not aggregate the community’s income because the authority cannot make lump sum transfers of income among households.

Given the utility weights, if a solution to the program exists it will identify one of the many possible efficient allocations. All of the efficient allocations obtainable given the existing distribution of income can be identified by varying the utility weights.

For the existing distribution of income and utility weights, assume that the solution to [9] is characterized by the following first order conditions:

$$
\lambda_{i} E_{g}\left\{\frac{\partial u_{i}}{\partial c_{i}} \frac{\partial c_{i}}{\partial x_{i j}}-\frac{\partial u_{i}}{\partial y_{i}} p_{j}+\frac{\partial u_{i}}{\partial a} \frac{\partial a}{\partial r_{i}} \frac{\partial r_{i}}{\partial x_{i j}}\right\}+\sum_{k \neq i} \lambda_{k} E_{g}\left(\frac{\partial u_{k}}{\partial a} \frac{\partial a}{\partial r_{i}} \frac{\partial r_{i}}{\partial x_{i j}}\right)=0, i=1, \ldots, n \text { and } j=1,2
$$

To interpret the first order condition it may be more informative to rewrite them in the following way:

$$
\lambda_{i} E_{g}\left\{\frac{\partial u_{i}}{\partial c_{i}} \frac{\partial c_{i}}{\partial x_{i j}}-\frac{\partial u_{i}}{\partial y_{i}} p_{j}\right\}=-E_{g}\left\{\sum_{k=1}^{n} \lambda_{k} \frac{\partial u_{k}}{\partial a} \frac{\partial a}{\partial r_{i}} \frac{\partial r_{i}}{\partial x_{i j}}\right\}, i=1, \ldots, n \text { and } j=1,2
$$


This is a modification of the usual Lindahl-Bowen-Samuelson conditions for the efficient provision of a public good. The modifications come from two sources: (1) the context of household heating and cooking decisions that affect the public good of urban air quality in the developing world, and (2) the uncertainty in the model — the stochastic weather effects on air pollution and household utility as well as uncertainty about the use of combustion technologies and wood input.

The left side of [11] is the government's weighted expectation of a household i's marginal non-environmental net benefit of employing input $j$. On the right side of [11] is government's expectation of the impact of that decision on the weighted sum of marginal disutilities from urban air pollution. Note that the sign of the right side of [11] depends on whether the energy input is the combustion technology or the wood input. For the combustion

technology $(j=1)$, the right side of [11] is negative because $\sum_{k=1}^{n} \lambda_{k}\left(\partial u_{k} / \partial a\right)<0, \partial a / \partial r_{i}>0$, and $\partial r_{i} / \partial x_{i 1}<0$. The negative sign indicates that the environmental authority's expectation of aggregate pollution damage is decreasing when a household employs a more efficient combustion technology. On the other hand, the right side of [11] is positive for the wood input ( $j$ $=2$ ), because $\partial r_{i} / \partial x_{i 2}>0$. The positive sign indicates that expected aggregate pollution damage is increasing in a household's use of wood.

\subsection{Efficient wood taxes and combustion technology subsidies}

Having characterized efficient allocations of combustion technologies and wood consumption, we now determine optimal taxes on wood consumption and subsidies for more efficient combustion technologies that will induce these choices. Clearly, these will be second-best optimal policies because of the authority's inability to make lump sum income transfers. 
A simple modification of [8] gives us the government's expectation of how households will respond to taxes and subsidies, $t_{i j} i=1, \ldots, n$ and $j=1,2$. Simply replace the $E_{i}$ 's in [8] with $E_{g}$ to reflect the fact that government uses its own expectation of households' decision criteria to determine optimal taxes and subsidies. ${ }^{10}$ After doing this substitute the result into [10] and rearrange terms to obtain

$$
t_{i j}=\frac{-E_{g}\left\{\sum_{k \neq i} \lambda_{k} \frac{\partial u_{k}}{\partial a} \frac{\partial a}{\partial r_{i}} \frac{\partial r_{i}}{\partial x_{i j}}\right\}}{E_{g}\left\{\lambda_{i} \frac{\partial u_{i}}{\partial y_{i}}\right\}}, i=1, \ldots, n \text { and } j=1,2 \text {. }
$$

The denominator of [12] is the regulator's expectation of household $i$ 's marginal utility of consumption of the private good times the weight assigned to that household. This term is positive. The numerator is the environmental authority's expectation of the marginal impact of household $i$ 's choice of input $j$ on weighted aggregate damage experienced by all the other households. This is the expected external cost (in the case of wood consumption) or benefit (in the case of combustion technology) from household $i$ 's decision. This term is negative if $j$ is the combustion technology, confirming that $t_{i 1}<0$ is a subsidy for the purchase of more efficient combustion technologies. The numerator is positive if $j$ is the wood input, confirming that $t_{i 2}>0$ is a tax on wood use.

\footnotetext{
${ }^{10}$ Obviously, we require that the government and households hold symmetric beliefs about the stochastic relationships between pollution damage, household emissions, and household choices.
} 


\section{The control of urban air pollution and the distribution of household income.}

The presence of welfare weights and the marginal utility of private good consumption in the taxes/subsidies in [12] means that the distribution of income will play an important role in optimal policies to control urban air pollution.

To understand how income disparity affects policy design, use [12] to subtract $t_{h j}$ from $t_{k j}$ for an arbitrary pair of households $h$ and $k$ and for both energy inputs $j=1$, 2. Carrying out this subtraction and rearranging terms yields

$$
t_{k j} \lambda_{k} E_{g}\left(\frac{\partial u_{k}}{\partial y_{k}}\right)-t_{h j} \lambda_{h} E_{g}\left(\frac{\partial u_{h}}{\partial y_{h}}\right)=-\lambda_{h} E_{g}\left(\frac{\partial u_{h}}{\partial a} \frac{\partial a}{\partial r_{k}} \frac{\partial r_{k}}{\partial x_{k j}}\right)-\left(-\lambda_{k} E_{g}\left(\frac{\partial u_{k}}{\partial a} \frac{\partial a}{\partial r_{h}} \frac{\partial r_{h}}{\partial x_{h j}}\right)\right) \text {. }
$$

On the right side of [13], $-\lambda_{h} E_{g}\left(\left(\partial u_{h} / \partial a\right)\left(\partial a / \partial r_{k}\right)\left(\partial r_{k} / \partial x_{k j}\right)\right)$ is the authority's expectation of the weighted impact of household $k$ 's choice of wood consumption or more efficient combustion technology on household $h$ 's disutility from pollution. Therefore, one potential source of variation of wood taxes and combustion technology subsidies across households stem from differences between the impacts of each household's choices on the pollution damage suffered by every other household. Since we are motivated by mid scale urban areas like Temuco, Chile with more than 80,000 households, the marginal impact of one household's choices on some other's utility is probably very small. Hence, we think it is reasonable to assume that right hand side of [13] is approximately zero so that

$$
t_{k j} \lambda_{k} E_{g}\left(\partial u_{k} / \partial y_{k}\right) \approx t_{h j} \lambda_{h} E_{g}\left(\partial u_{h} / \partial y_{h}\right) \text {, for all household pairs } k \text { and } h \text {, and } j=1,2 \text {. }
$$

For some household $i$ and with $j$ being the wood input, $t_{i j} \lambda_{i} E_{g}\left(\partial u_{i} / \partial y_{i}\right)$ is the government's weighted expectation of the household's marginal cost of the wood tax in terms of utility of consuming the private good. For the combustion technology, the term is the authority's 
weighted expectation of the household's marginal benefit of the technology subsidy. The result in [14] indicates that the weighted expectation of the marginal cost of the wood tax should be approximately equal across households. The same is true of the combustion technology subsidy. This is reminiscent of the requirement to equate marginal abatement costs of commercial point pollution sources to minimize the aggregate abatement costs of pollution control.

Our result in [14] also indicates that taxes and subsidies vary across households as $\lambda_{i} E_{g}\left(\partial u_{i} / \partial y_{i}\right)$ varies over households. Of course, the marginal utility of consumption of the private good, $\partial u_{i} / \partial y_{i}$, varies with household income. Diminishing marginal utility of consumption of the private good implies that $\partial u_{i} / \partial y_{i}$ decreases as household $i$ 's income increases. Therefore, [14] indicates that the distribution of income plays an important role in formulating policies to control urban air pollution from households.

In fact, $\lambda_{i} E_{g}\left(\partial u_{i} / \partial y_{i}\right)$ only varies across households if the authority is unable or unwilling to make unrestricted lump sum income transfers. When an authority makes these transfers, $t_{k j} \approx t_{h j}$ for all household pairs $k$ and $h$, and $j=1$, 2. To see this, modify the social decision problem [9] by eliminating the individual household budget constraints and replacing them with the single aggregate income constraint,

$$
\sum_{i=1}^{n} w_{i}=\sum_{i=1}^{n} y_{i}+p_{1} \sum_{i=1}^{n} x_{i 1}+p_{2} \sum_{i=1}^{n} x_{i 2} \text {. }
$$

This modification allows an authority to distribute the aggregate income of the community in any way it wants. Let $\phi>0$ be the multiplier attached to the aggregate wealth constraint for the Lagrange equation for the problem. Then, the first order conditions for determining the allocation of wood use and combustion technologies are: 
[15] $\quad \lambda_{i} E_{g}\left(\frac{\partial u_{i}}{\partial c_{i}} \frac{\partial c_{i}}{\partial x_{i j}}+\frac{\partial u_{i}}{\partial a} \frac{\partial a}{\partial r_{i}} \frac{\partial r_{i}}{\partial x_{i j}}\right)+\sum_{k \neq i} \lambda_{k} E_{g}\left(\frac{\partial u_{k}}{\partial a} \frac{\partial a}{\partial r_{i}} \frac{\partial r_{i}}{\partial x_{i j}}\right)-\phi p_{j}=0, i=1, \ldots, n$ and $j=1,2$, and the first order conditions for determining consumption of the private good are

$$
\lambda_{i} E_{g}\left(\partial u_{i} / \partial y_{i}\right)-\phi=0, i=1, \ldots, n
$$

Combine [15] and [16] to obtain

$$
\begin{aligned}
& \lambda_{i} E_{g}\left(\frac{\partial u_{i}}{\partial c_{i}} \frac{\partial c_{i}}{\partial x_{i j}}+\frac{\partial u_{i}}{\partial a} \frac{\partial a}{\partial r_{i}} \frac{\partial r_{i}}{\partial x_{i j}}\right)+\sum_{k \neq i} \lambda_{k} E_{g}\left(\frac{\partial u_{k}}{\partial a} \frac{\partial a}{\partial r_{i}} \frac{\partial r_{i}}{\partial x_{i j}}\right)-\lambda_{i} E_{g}\left(\frac{\partial u_{i}}{\partial y_{i}}\right) p_{j}=0, \\
& i=1, \ldots, n \text { and } j=1,2 .
\end{aligned}
$$

Note that [17] is the same as [10]. Therefore, combining this with [8] with $E_{i}$ replaced by $E_{g}$ yields [12] and ultimately [14]. However, the major difference in assuming the government has the unrestricted ability to make lump sum transfers comes from [16], which implies

$$
\lambda_{k} E_{g}\left(\partial u_{k} / \partial y_{k}\right)=\lambda_{h} E_{g}\left(\partial u_{h} / \partial y_{h}\right) \text {, for all household pairs, } k \text { and } h \text {. }
$$

This implies that the efficient pollution control policy would include income transfers so that households' weighted expected marginal utilities of consumption of the private good are equal. For given utility weights and diminishing marginal utility of private good consumption, these income transfers would tend to be from richer households to poorer ones. If these transfers are made, [18] indicates that $\lambda_{i} E_{g}\left(\partial u_{i} / \partial y_{i}\right)$ plays no role in how an optimal control policy treats different households. That is, efficient lump sum income transfers would imply that household wood taxes and combustion technology subsidies satisfy $t_{k j} \approx t_{h j}$, for all household pairs $k$ and $h$, and $j=1,2$.

However, as we noted earlier it is unlikely that these income transfers would be made a part of policies to control household air pollution. In this case, the effect of income disparity on 
the efficient pollution control policy cannot be dealt with directly, but instead must be dealt with through the specification of household utility weights or through the variation in wood taxes and technology subsidies across households. The first option would make $\lambda_{i} E_{g}\left(\partial u_{i} / \partial y_{i}\right)$ the same for all households by varying the $\lambda_{i}$ 's . Since $\partial u_{i} / \partial y_{i}$ will be higher for lower income households, this strategy would assign lower weights in the social welfare function to these households. It is hard to imagine a policy that is more arbitrary and unfair.

Varying the wood taxes and combustion technology subsidies seems to us to be more defensible. From [14] it is easy to see that both the wood tax and the subsidy for more efficient combustion technologies will tend to be higher for higher income households. That is, if $k$ is a wealthier household than $h$, then the combustion technology subsidies satisfy $-t_{k 1}>-t_{h 1}$, and the wood consumption taxes satisfy $t_{k 2}>t_{h 2}$.

At first glance it may seem paradoxical that income differences call for a higher subsidy for wealthier households. However, the reason that efficiency calls for wealthier households to take on more of the burden of reducing air pollution than less wealthy households is to distribute the expected marginal utility costs of wood taxes and benefits of technology subsidies so they are equal. With lump sum transfers this equilibration is accomplished by income redistribution. In the absence of these transfers it is accomplished by pushing more of the control burden onto wealthier households. To see why wealthier households take on more of the burden let us assume that we can tax household emissions directly. We will show that the emissions tax is higher for wealthier households in the absence of lump sum income transfers, thereby demonstrating that efficiency calls for wealthier households to take on more of the burden of air pollution control. 
Assume that the $i^{\text {th }}$ household faces an emissions tax $t_{i}$ on its emissions $r_{i}$, instead of tax on its wood consumption and a subsidy for more efficient combustion technologies. Then the household's decision problem is to choose $x_{i 1}, x_{i 2}$, and $y_{i}$ to solve

$\max E_{i}\left(u_{i}\left(c_{i}, y_{i}, a, \mu, \eta_{i}\right)\right)$

s.t. $\quad c_{i}=c\left(x_{i 1}, x_{i 2}\right)$,

$$
\begin{aligned}
& w_{i}=y_{i}+p_{1} x_{i 1}+p_{2} x_{i 2}+t_{i} r_{i}\left(x_{i 1}, x_{i 2}, \sigma_{i}\right), \\
& a=a\left(\sum_{k=1}^{n} r_{k}\left(x_{k 1}, x_{k 2}, \sigma_{k}\right), \theta\right) .
\end{aligned}
$$

The first-order conditions are:

$$
E_{i}\left\{\frac{\partial u_{i}}{\partial c_{i}} \frac{\partial c_{i}}{\partial x_{i j}}-\frac{\partial u_{i}}{\partial y_{i}}\left(p_{j}+t_{i} \frac{\partial r_{i}}{\partial x_{i j}}\right)+\frac{\partial u_{i}}{\partial a} \frac{\partial a}{\partial r_{i}} \frac{\partial r_{i}}{\partial x_{i j}}\right\}=0, i=1, \ldots, n, j=1,2
$$

As before, replace the $E_{i}$ 's in [20] with $E_{g}$ to reflect the fact that government uses its own expectation of the households' decision criteria to determine optimal taxes and subsidies. After doing this, substitute the result into [10] and rearrange terms to obtain

$$
t_{i}=\frac{-\sum_{k \neq i} \lambda_{k} E_{g}\left(\frac{\partial u_{k}}{\partial a} \frac{\partial a}{\partial r_{i}} \frac{\partial r_{i}}{\partial x_{i j}}\right)}{\lambda_{i} E_{g}\left(\frac{\partial u_{i}}{\partial y_{i}} \frac{\partial r_{i}}{\partial x_{i j}}\right)}, i=1, \ldots, n .
$$

To simplify matters, assume that the uncertainty in $\partial r_{i} / \partial x_{i j}, j=1,2$ is uncorrelated with the uncertainty in $\partial u_{i} / \partial y_{i}$ and in $\left(\partial u_{k} / \partial a\right)\left(\partial a / \partial r_{i}\right)$, for all $i=1, \ldots, n$. This allows us to 
eliminate $\partial r_{i} / \partial x_{i j}$ from [21]. ${ }^{11}$ Once this has been done, subtract $t_{h j}$ from $t_{k j}$ to obtain

$$
t_{k} \lambda_{k} E_{g}\left(\frac{\partial u_{k}}{\partial y_{k}}\right)-t_{h} \lambda_{h} E_{g}\left(\frac{\partial u_{h}}{\partial y_{h}}\right)=-\lambda_{h} E_{g}\left(\frac{\partial u_{h}}{\partial a} \frac{\partial a}{\partial r_{k}}\right)-\left(-\lambda_{k} E_{g}\left(\frac{\partial u_{k}}{\partial a} \frac{\partial a}{\partial r_{h}}\right)\right)
$$

Again, the right side expression is likely to be very small, so [22] implies $t_{k} \lambda_{k} E_{g}\left(\partial u_{k} / \partial y_{k}\right) \approx$ $t_{h} \lambda_{h} E_{g}\left(\partial u_{h} / \partial y_{h}\right)$, for all household pairs $k$ and $h$. If the authority can tax household emissions but cannot make lump sum transfers of income across households, [22] suggests that the efficient tax on emissions is higher for higher income households. Thus, optimality calls for making higher income households bear more of the burden of controlling household air pollution.

Of course, we have maintained that the main difficulty in this policy problem is that household emissions cannot be observed. When an authority can control wood consumption and combustion technologies it pursues policies that place more of the air pollution control burden on higher income households by placing a higher tax on their wood consumption and offering a higher subsidy for their purchase of more efficient combustion technologies. It is important to realize that a higher technology subsidy for wealthier households is not meant to correct income inequality. The purpose of the subsidy is to motivate the purchase of more efficient combustion technologies. A higher technology subsidy for wealthier households is a part of how more control burden is optimally placed on wealthier households. It bears repeating, however, that the technology subsidy is only needed because household emissions cannot be controlled directly. Thus, it is the nonpoint nature of the problem combined with the inability of an authority to make

\footnotetext{
11 This lack of correlation could come about, for example, if there was no regulatory uncertainty about how household choices of wood consumption and combustion technology produce emissions. If we are not able to eliminate $\partial r_{i} / \partial x_{i j}$ from the right side of [21], a household's emission tax would depend on the input $j$. In this case, no emissions tax could simultaneously satisfy [20] for both the wood input and the combustion technology. This problem is discussed in another context by Shortle and Horan (2001).
} 
unrestricted lump sum income transfers that lead to higher technology subsidies for wealthier households.

\section{Concluding remarks about implementation}

We have derived a set of efficient household-specific taxes on wood consumption and subsidies for more efficient combustion technologies. Our most important result is that these interventions are dependent of the distribution of income; in fact, efficiency requires that these taxes and subsidies be structured so that wealthier households take on more of the control burden. In this section we discuss some practical implementation issues associated with our results.

Although we have assumed that taxes on wood consumption and subsidies for combustion technologies are available, in many settings in the developing world wood consumption is not observable. This may be due to the absence of formal markets for wood for heating, which is the case of wood used by urban households in central southern Chile. The market for wood is mainly informal and no regulatory authority has actual control or transaction records. In a recent survey of a sample of urban households in the city of Temuco, about $90 \%$ of the respondents acknowledged buying wood without paying taxes (CONAMA-DICTUC 2008).

In the absence of the ability to monitor wood consumption, air pollution control policy would then focus on promoting cleaner combustion technologies. However, our result that income disparities imply that higher technology subsidies should be provided to higher income households becomes problematic. It is hard to imagine that there would be much political support for our recommendation.

In fact, it may be the case that subsidies are only feasible if they are targeted at lower income groups. This is likely to be true in Chile where subsidies that are part of social welfare programs are targeted at the poor. We are not aware of any environmental policy intervention in 
Chile that uses subsidies for household choices; however, it seems likely that such a policy would be implemented in concert with social policies that define how subsidies are allocated. Providing a higher technology subsidy to higher income households might appear to be at odds with other social welfare objectives.

While higher technology subsidies for higher income households may be part of an efficient control program, they may not be part of a control policy that pursues other reasonable objectives. For example, an authority may be motivated to get the largest improvement in air quality with a limited budget to pay subsidies for more efficient combustion technologies. Then it may be the case that these subsidies should be directed mainly at poorer households if this is where the marginal reduction in emissions from a dollar of technology subsidy is highest. Pursuing the biggest environmental improvement for a fixed implementation budget is a reasonable policy objective, even though it will not lead to the theoretically efficient solution. However, it may be easier to understand than the idea of efficiency, and hence, easier to sell to lawmakers and the public.

Even though we have assumed that combustion technologies are observable, and therefore can be subsidized, there is still a costly enforcement problem to manage. A monitoring and penalty program needs to be designed along with the incentive policy to make sure that those who take advantage of the subsidy actually purchase approved equipment and use it properly.

Our results suggest that optimal technology subsidies and wood taxes vary continuously according to household incomes. While continuity is possible because authorities are likely to have income information for tax purposes, it is more likely that authorities will group households into a relatively small number of income classes and apply different subsidies and taxes to each class. Differentiated after-tax or after-subsidy prices produce the risk of developing so-called 
"black markets" in wood or combustion equipment. Black markets could also develop across communities that move efficient combustion equipment intended for one community to another. If this problem proves difficult to deal with, then authorities could be forced to consider implementing a uniform technology subsidy or wood tax despite the efficiency consequences.

Our results also suggest that the efficient subsidies (and wood taxes if they are available) should vary across cities. Although we have illustrated the problem of concern with the case study of Temuco in southern Chile, the same type of air pollution is a serious problem in several medium and small size cities in the valley south of the Chilean capital of Santiago. Because of the heterogeneity across these cities in terms of population, income distribution, distribution of combustion technologies, the use of wood, and general environmental conditions, it is highly unlikely that the same control policy will be appropriate for different cities.

A coordinated plan may also be required to manage the flow of retired equipment across communities. An effective equipment subsidy program will generate a stock of discarded stoves. If these are not destroyed, they may be available to other communities at significantly reduced prices. Because of this a stove replacement program in one community can have environmental impacts in other communities; hence, the potential need for coordinated air quality programs.

\section{Acknowledgments}

We gratefully acknowledge financial support from Conicyt-Chile under Project Fondecyt No 1080287 and Fondecyt International Cooperation. 


\section{References}

Barna, M., Gimson, N., 2002. Dispersion modeling of wintertime particulate pollution episode in Christchurch, New Zealand. Atmospheric Environment 36(21): 3531-3544.

Bovenberg, L., Goulder, L., 2002. Environmental taxation and regulation. In Handbook of Public Economics Volume 3 Part 2. Alan Auerbach and Martin Feldstein (Eds.). North-Holland.

Chávez, C., Gómez, W., Briceño, S., 2009. Costo-efectividad de instrumentos económicos para el control de la contaminación. El caso del uso de leña. Cuadernos de Economía 46: 197-224.

Chichilnisky, G., Heal, G., 1994. Who should abate carbon emissions? Economic Letters 44: 443-449.

CONAMA- DICTUC, 2008. Actualización del inventario de emisiones atmosféricas en las comunas Temuco y Padre Las Casas.

CONAMA, 2007. Anteproyecto de plan de descontaminación atmosférico para las comunas de Temuco y Padre Las Casas. Resolución Exenta No 1190.

Environment Canterbury (ECAN), 2009. Environment Canterbury Anual Report 2008/2009, Christchurch, New Zealand.

Gómez-Lobo, A., 2005. El consumo de leña en el sur de Chile: ¿por qué nos debe preocupar y qué se debe hacer?. Revista Ambiente y Desarrollo 21(3): 43-47.

Heal, G., Chichilnisky, G., Starret, D., 1993. Equity and efficiency in environmental markets: global trade in $\mathrm{CO}_{2}$ emissions. PaineWebber Working Paper Series in Money, Economics and Finance, Columbia Business School, http://www.columbia.edu/cu/business/wp/

Hearth, Patio \& Barbecue Association (HPBA), 2008. “Clearing the Smoke. The Wood Stove Changeout in Libby, Montana”. Preliminary Report.

Kesby, P., Bagchi, K., Carnovale, F., Abernethy, I., 2002. Improving Launceston's air- a collaborative approach to reducing wood heater emissions. In: Conference Proceedings 16th International Clean Air and Environment Conference, Clean Air Society of Australia and New Zealand: 403-408.

Klippel, N., Nussbaumer T., 2007. Einfluss der betriebswise auf die partiklemissionen von holzofen (Influence of operation type on particulate emissions from residential wood combustion). Bundersamt fur Energie, Bern, ISBN 3-908705-15-0.

Laffont, J.-J., 1988. Fundamentals of Public Economics. MIT Press, Cambridge, Massachusetts.

Lobos, M., 2001. Estudio preliminar sobre producción, comercialización y consumo de leña en la ciudad de Temuco. WWF-CODEFF. Documento No 3, Serie de Publicaciones WWF Chile, Programa Ecoregión Valdiviana.

Luhar, A., Galbally, I., Keywood, M., 2006. Modelling PM10 concentrations and carrying capacity associated with woodheater emissions in launceston, Tasmania. Atmospheric Environment 40, pp. 5543-5557.

Ministry of the Environment. British Columbia, 2005. Residential wood-burning emissions in British Columbia” (electronic resource), available on the internet: www.env.gov.bc.ca/epd/bcairquality/reports/pdfs/wood_emissions.pdf

Nussbaumer, T., 2006. Results from tests on wood stoves and revised recommendations for emission limit values for Chile. Report for CONAMA and COSUDE, Verenum, Zurich.

Nussbaumer, T., 2003. Combustion and co-combustion of biomass: fundamentals, technologies, and primary measures for emission reduction. Energy \& Fuels 17: 1510-1521. 
Sacramento Metropolitan Air Quality Management District, 2008. Adopt a resolution approving the proposed changes to wood stoves/fireplace change out incentive program and authorizing FY08/09 funding.

Sacramento Metropolitan Air Quality Management District, 2006. Wood stoves \& fireplace change out incentive program. Prepared by Ali Mohamed, Associate Air Quality Engineer.

Sandmo, A., 1975. Optimal taxation in the presence of externalities. Swedish Journal of Economics 77(1): 86-98.

Segerson, K., 1988. Uncertainty and incentives for nonpoint pollution control. Journal of Environmental Economics and Management 15: 133-148.

Sheeran, K., 2006. Who should abate carbon emissions? A note. Environmental and Resource Economics 35: 89-98.

Shortle, J., Horan, R., 2001. The economics of nonpoint pollution control. Journal of Economic Surveys 115(3): 255-289.

Von Baer, D., Hellwing, M., Farías, O., Cerda, a., Rivas, R., Drake, F., Zacarías, M., Mellado, A., 2002. Priorización de medidas de reducción de emisiones por uso residencial de leña para la gestión de la calidad del aire en Temuco y Padre Las Casas. Estudio Universidad de Concepción para la Comisión Nacional del Medio Ambiente (CONAMA).

Wilton, E., Smith, J., Dey, K., Webley, W., 2006. Real life testing of woodburners emissions. Clean Air and Environmental Quality 40(4), pp.43-47.

World Health Organization, 2005. WHO Air Quality Guidelines Global Update 2005. 